\title{
Systemic Risk of Conventional and Islamic Banks: Comparison with Graphical Network Models
}

\author{
Shatha Qamhieh Hashem, Paolo Giudici \\ Department of Economics and Management Science, University of Pavia, Pavia, Italy \\ Email: shatha.hashem01@universitadipavia.it, paolo.giudici@unipv.it
}

How to cite this paper: Hashem, S.Q. and Giudici, P. (2016) Systemic Risk of Conventional and Islamic Banks: Comparison with Graphical Network Models. Applied Mathematics, 7, 2079-2096.

http://dx.doi.org/10.4236/am.2016.717166

Received: August 11, 2016

Accepted: November 11, 2016

Published: November 14, 2016

Copyright $\odot 2016$ by authors and Scientific Research Publishing Inc. This work is licensed under the Creative Commons Attribution International License (CC BY 4.0).

http://creativecommons.org/licenses/by/4.0/

\begin{abstract}
The main aim of this paper is to compare the stability, in terms of systemic risk, of conventional and Islamic banking systems. To this aim, we propose correlation network models for stock market returns based on graphical Gaussian distributions, which allows us to capture the contagion effects that move along countries. We also consider Bayesian graphical models, to account for model uncertainty in the measurement of financial systems interconnectedness. Our proposed model is applied to the Middle East and North Africa (MENA) region banking sector, characterized by the presence of both conventional and Islamic banks, for the period from 2007 to the beginning of 2014. Our empirical findings show that there are differences in the systemic risk and stability of the two banking systems during crisis times. In addition, the differences are subject to country specific effects that are amplified during crisis period.
\end{abstract}

\section{Keywords}

Financial Stability, Centrality Measures, Graphical Gaussian Models, Islamic Banks, Conventional Banks, Systemic Risk

\section{Introduction}

The late 2007-2008 global financial crisis has assured the importance of financial systems' stability and soundness under a systemic risk event. The crisis also highlighted the difference between Islamic and conventional banks in terms of their stability. Even though Islamic banks faced the challenges encountered by their conventional peers during the financial crisis, they managed to achieve an average growth rate of $20 \%$ after 2009 ([1]). The high growth rate and the resilience abilities of the Islamic banking model attracted the conventional financial sector participants to consider the use of Islamic finance characteristics as a means of financial stability. This has stimulated re- 
search, aimed at comparing Islamic and conventional banks in terms of risks and performances. An Islamic bank is a financial institution that is engaged in all banking activities at a zero-interest rate according to Islamic Shariah rules (see e.g. [2]). In addition, it is allowed to share profit and loss (PLS) between the provider and the user of funds, but all its transactions should be backed by real tangible assets, with restrictions on taking excessive uncertainty (gharar) as in the use of derivatives, or excessive risk taking (maysar) as in gambling, or financing any business activity that is not ethically accepted (only halal activities are allowed). The governor of the Malaysian central bank ([3]), asserted in a speech the protection from risk that an Islamic bank has as a result of its business model features. However, [4] found that a strong connection to the real economy will increase the system exposure to contagion effects, which challenges the stability of Islamic banks in a novel way due to its strong connection to the real economy.

Usually, Islamic banks stability is inferred through comparative risk analysis with conventional banks. [5] indicated that in Pakistan, loans default rates of conventional banks are almost twice those of Islamic ones. [6] found a size affect on the bank risk level, with a favorable stability effect for the small Islamic banks, whereas the stability of large banks are in favor of the conventional ones. In a similar study, the z-score indicator has shown that Islamic banks are more stable than conventional ones, but the significance of the difference vanishes for large banks ([7]). Finally, [8] found a lower distance to insolvency for Islamic banks and confirmed the size effect, but highlighted the presence of large cross country differences.

In addition to the previous stability inference based on the z-score measure, Islamic banks stability is also assessed based on market risk. [9] found that Islamic banks have better credit and asset growth, which contributed to the financial system stability during the crisis time, and allowed them to receive a more favorable risk assessment from external rating agencies. A related study concluded that the PLS feature of Islamic banks can reduce the market risk, but this is subject to the risk mitigation techniques used by them ([10]). [11] suggested that Islamic banks can complement, rather than substitute, conventional banks, which may be helpful to the overall financial stability through diversification. [12] showed that in general, the two banking models have no significant difference in spite Islamic banks higher return on assets, they also pointed out that Islamic banks have deviated from their model towards the conventional one, which puts their resilience under the pressure of the financial crisis.

From the previous discussion, we note that the literature does not directly consider the measurement of Islamic banks systemic risk. In addition, and to our knowledge, the issue of evaluating Islamic banks systemic risk, through modelling their interconnectedness within the financial system, has not yet been addressed, and has overlooked the process of systemic risk assessment that considers the financial system as a network of institutions with linkages, which allows the systemic risk and the financial distress to be transfered and magnified during crisis times, as applied by [13]. Furthermore, the literature does not directly assess the systemic risk implication that Islamic banks have on 
the countries which include both conventional and Islamic banking activities. We aim to fill this gap through studying Islamic banks' systemic risk impact on the financial system of the countries where they operate. This is in line with [8] findings, as our objective is to take into account the presence of cross country differences.

Our contribution tries to take into consideration the two prevailing research viewpoints present in the literature of Islamic banking stability. The first questions if there is a real difference between the Islamic and conventional banking systems (see e.g. [14] [15]); we address this point by including countries with a full Islamic or a full conventional banking system, if no difference is found between the two pure systems, then the Islamic and conventional banking systems are alike. The second suggests that the two models are different and may be complementary once the relative strengths and weaknesses are understood ([16] [17] [18] [19]); we address this point by measuring the systemic risk for countries that operate both Islamic and conventional banking systems, and compare them to the two pure system.

The main aim of this paper is to investigate whether including Islamic banking activities within a country's banking system supports the financial performance and stability at the country level. To achieve this purpose, we compare countries that operate either conventional or Islamic banking systems with those that operate both. We apply this study on the publicly trade banks located within the countries of the Middle East and North Africa (MENA) region, as the majority of the Islamic banking activities are settled there. The MENA region is found to hold $78.57 \%$ of the total global Islamic banking assets, with the GCC countries holding $38.19 \%$ of this total ([1]).

The methodological contribution of this paper is aimed at providing a statistical model that allows to compare banking systems in terms of their systemic implications using financial networks, based on graphical Gaussian models. Graphical Gaussian models were introduced in multivariate statistics to model complex relationships between many variables (see e.g. [20]). Recently, they have been found as powerful alternatives to measure systemic risk, with respect to fully connected network models, see for instance, the papers by [21], and [22].

Country level Graphical models allow us to avoid the heterogeneity of the results at the individual banks level, especially that the available literature assess Islamic banks' stability based on the individual bank level, whether using z-score or other risk indicators, which captures the idiosyncratic effects, but misses the systemic interconnectedness component, and overlooks the definition of systemic risk as a macroeconomic event that causes simultaneous severe losses for market participants as it diffuse through the system ([23]). Thus, the advantage of using graphical models is to provide a measurement for systemic risk that, differently from the classical risk comparisons and the $\mathrm{z}$-score measure, takes into account the multivariate dependencies between the agents involved (banking systems).

We believe that the implications of our research results can be beneficial to regulators and central banks in terms of Islamic banking activities effect on the countries' financial and economic stability during a crisis period. Conventional banks can gain in- 
sight regarding the effect of diversifying their services with Islamic banking activities on the bank's risk profile, especially that in the last years several conventional banks from Europe, UK and the USA are being involved in Islamic banking activities. Finally, fund providers and investors may benefit from the research in making portfolio allocation decisions.

The paper is organized in five sections. The second section provides the proposed methodology, based on graphical Gaussian models and the centrality measures obtained from them. The third section describes the data and the application of the proposed models. And the final section provides the research conclusions.

\section{Graphical Gaussian Network Models}

The research field of systemic risk has emerged after the recent financial crisis. Several empirical studies have been carried out to determine the degree of contagion between conventional banks and the related financial systems.

Specific measures of systemic risk have been proposed by [24] [25] [26] [27] and [28]. All of these approaches are built on financial market price information, in which they lead to assessing the financial institution's appropriate quantiles of the estimated loss probability distribution, conditional on a crash event in the financial market. They however do not address the issue of how risks are transmitted between different institutions.

Trying to address this aspect of systemic risk, researchers have recently introduced financial network models. In particular, [29] propose several econometric measures of connectedness based on principal component analysis and Granger-causality networks. [30] propose Vector Autoregressive models, augmented with a LASSO type estimation procedure, aimed at selecting the significant links in a network model. [31] and [32] propose tail dependence network models aimed at overcoming the bivariate nature of the available systemic risk measures.

Network models, albeit elegant and visually attractive, are based on the assumption of full connectedness among all institutions, which makes their estimation and interpretation quite difficult, especially when a large number of them is being considered. To tackle the previous limitation, [22] and [21] have recently introduced graphical correlation models, which can account for partial connectedness, expressed in terms of conditional independence constraints. A similar line of research has been followed by [33], who have introduced multivariate Brownian processes with a correlation structure that is determined by a conditional independence graph.

Our contribution follows the latter perspective, and employs graphical network models to understand and compare the different banking systems in terms of systemic risk and its transmission mechanisms. To achieve this aim we use the closing price for the corresponding banks' shares, and we measure how such prices correlate. The data is assumed to be generated by a stationary process, with the mean $\mu=0$. To achieve stationarity, we transform stock prices into stock returns that are expressed, as usual, in time variation. 
Formally, if $V_{t}$ and $V_{t-1}$ are the closing stock prices at times $t$ and $t-1$, the variation represents the returns denoted by $w(t)$, such that: $w(t)=V_{t}-V_{t-1} / V_{t-1}$, where $V_{t-1} \neq 0$.

In our framework, we consider a cross-sectional perspective to understand the change in systemic risk transmission mechanism in relation to the presence and absence of the financial crisis, in which the systemic risk can be depicted by a network that describes the mutual relationships between the different banking systems involved. Correlation based networks are suitable to visualize the structure of pairwise marginal correlations among a set of nodes $N$ that corresponds to the investigated banking systems. Each banking system represents a node in the network, and each pair of nodes can be connected by an edge, which has a weight related to the correlation coefficient between the two nodes. Furthermore, the banking systems that comprise a network of $N$ nodes can be described by an associated $N \times N$ matrix of weights, named adjacency matrix $A$, with each element in the matrix referenced as $a_{i, j}$. However, since the aim of the research is to focus on the structure of the interconnections, and less on the interconnectedness magnitude, the adjacency matrix $A$ can be made binary $(0,1)$, by setting $a_{i, j}=1$ when two nodes are correlated, and $a_{i, j}=0$ when they are not correlated.

Another issue that relates to correlation networks initialization is the specification of the correlation itself, as being marginal against being partial. It is known that the use of pairwise marginal correlations will measure both the direct and the indirect effect of one network node on another. On the other hand, the use of pairwise partial correlations will measure only the direct effect between the two network nodes, excluding the mediation of others, which better servers our purpose of modelling the systemic risk of each node, or in other words, the systemic risk of each banking system.

From a statistical viewpoint, marginal correlations can be estimated on the basis of the observed $N$ time series, in which each time series contains the return data of a specific banking system, under the assumption that the observations follow a multivariate Gaussian model, with unknown variance-covariance matrix $\Sigma$. As for partial correlations, they can be estimated assuming that the same observations follow a graphical Gaussian model, in which the variance-covariance matrix $\Sigma$ is constrained by the conditional independence described by a graph (see e.g. [20] [34]; or from an econometric viewpoint, [35] [36]).

More formally, let $x=\left(x_{1}, \cdots, x_{N}\right) \in R^{N}$ be a $N$-dimensional random vector (a returns vector), distributed according to a multivariate normal distribution $\mathcal{N}_{N}(\mu, \Sigma)$, where $\mu$ is the mean, and $\Sigma$ is the covariance matrix which we assume throughout the work that it is not singular.

The network model is represented by an undirected graph $G$, such that $G=(V, E)$, with $V=\{1, \cdots, N\}$ being the vertex set (nodes), and $E=V \times V$ being the edge set. $G$ is described with a binary adjacency matrix $A$, that has elements $e_{i j}$, which provides the information of whether pairs of vertices in $G$ are (symmetrically) linked between each other $\left(e_{i j}=1\right)$, or not $\left(e_{i j}=0\right)$. If the vertices $V$ of this graph are put in corre- 
spondence with the random variables $X_{1}, \cdots, X_{N}$, in which each $X$ refers to the time series of a specific banking system stock returns, the edge set $E$ induces conditional independence on $X$ via the so-called Markov properties (see e.g. [20]). More precisely, the pairwise Markov property determined by $G$ states that, for all $1 \leq i<j \leq N$ :

$$
e_{i j}=0 \Leftrightarrow X_{i} \perp X_{j} \mid X_{V \backslash\{i, j\}}
$$

this indicates that, the absence of an edge between two vertices, $i$ and $j$, is equivalent to the independence between the random variables $X_{i}$ and $X_{j}$, conditionally on all the other variables $x_{V \backslash\{i, j\}}$.

In our context, all random variables are continuous and are assumed to be normally distributed, with each $X \sim \mathcal{N}_{N}(0, \Sigma)$, and with the elements of the inverse of the variance-covariance matrix $\Sigma^{-1}$ being indicated as $\left\{\sigma^{i j}\right\} .[34]$ proved that the following equivalence also holds:

$$
X_{i} \perp X_{j} \mid X_{V \backslash\{i, j\}} \Leftrightarrow \rho_{i j V}=0
$$

where

$$
\rho_{i j V}=\frac{-\sigma^{i j}}{\sqrt{\sigma^{i i} \sigma^{i j}}}
$$

$\rho_{i j V}$ denotes the $i j$-th partial correlation, that is, the correlation between $X_{i}$ and $X_{j}$ conditionally on the remaining variables $X_{V\{i, j\}}$. Therefore, by means of the pairwise Markov property, and given an undirected graph $G=(V, E)$, a graphical Gaussian model can be defined as the family of all $N$-variate normal distributions $\mathcal{N}_{N}(0, \Sigma)$ that satisfy the constraints induced by the graph on the partial correlations for all $1 \leq i<j \leq N$, as follows:

$$
e_{i j}=0 \Leftrightarrow \rho_{i j V}=0
$$

In practice, the available data will be used to test which partial correlations are different from zero at the chosen significance level threshold $\alpha$. This leads to the selection of a graphical model on which all inferences are conditioned and from which the systemic risk is determined.

To summarize the systemic risk form the network that we estimated on the basis of the graphical Gaussian model, network centrality measures are used. The most important summary measure that has been proposed in financial network modeling, to explain the capacity of an agent to cause systemic risk, as a large contagion loss on other agents, is eigenvector centrality (see e.g. [29] [37]). Eigenvector centrality measures the systemic risk of a node based on the importance of that node in the network. This is done by assigning relative scores to all nodes in that network, using the principle that connections to few high scoring nodes contribute more to the score of the node in question than an equal number of connections to low scoring nodes.

More formally, for the $i$-th node, the eigenvector centrality score $E g_{i}$ is proportional to the sum of the scores of all nodes which are connected to it, as in the following equation: 


$$
E g_{i}=\frac{1}{\lambda} \sum_{j=1}^{N} a_{i, j} E g_{j}
$$

where $E g_{j}$ is the eigenvector centrality score of the $j$-th node, $\lambda$ is a constant, $a_{i, j}$ is the $(i, j)$ element in the adjacency matrix $A$ of the network, and $N$ is the number of nodes in the network. The previous equation can be rewritten in terms of all nodes, more compactly, as:

$$
A E g=\lambda E g
$$

where $\lambda$ is the eigenvalue of the matrix $A$ and $E g$ is the associated eigenvector for an $N$-vector of scores (one score vector for each node). Note that, in general, there will be many different eigenvalues $\lambda$ for which a solution to the previous equation exists. However, the additional requirement that all the elements of the eigenvectors be positive (a natural request in our context) implies (by the Perron-Frobenius theorem) that only the eigenvector corresponding to the largest eigenvalue provides the desired centrality measures. Therefore, once an estimate of $A$ is provided, network centrality scores can be obtained from the previous equation, as elements of the eigenvector associated to the largest eigenvalue.

A different, and simpler to interpret, measure of systemic risk is node degree, which is a measure of the number of links that are significantly present in the selected model, between a node and all others. For a node $i$ in a graphical model with nodes $j=1, \cdots, n$, let $e_{i j}$ represent a binary variable that indicates whether a link between $i$ and $j$ is present ( 1 ) or not (0), then node degree is:

$$
d_{i}=\sum_{j=1}^{N} e_{i j}
$$

Both the previously introduced measures are based on the adjacency matrix of a correlation network and depend, therefore, only on the presence or absence of a link between two nodes, and not on the actual (direct) dependence between them. To introduce such dependence we can extend the node degree measure $d_{i}$ into a partial correlation node degree $\rho d_{i}$, that employs partial correlations as weights, the measure formula is:

$$
\rho d_{i}=\sum_{j=1}^{N} e_{i j}\left|\rho_{i j V}\right|
$$

In the application section, we compare node degree, partial correlation degree and eigenvector centrality measures. Before moving to the application, we remark that the measures are conditioned on the chosen graph and, therefore, may be quite unstable, depending on the results of the selection procedure.

To check the robustness of our results, a Bayesian approach can be followed so that the centrality measures can be estimated without being conditioned on the chosen graph, as in the classical approach, but rather as a model average between different graphs, each with a weight that corresponds to its posterior probability, and is repeated on a yearly base rolling window. 
To achieve this aim, the first task is to recall the expression of the marginal likelihood of a graphical Gaussian model, and specify prior distributions over the parameter $\Sigma$ as well as on the graphical structures $G$. For a given graph $G$, consider a sample $X$ of size $n$ from $P=\mathcal{N}_{N}(0, \Sigma)$, and let $S_{n}$ be the corresponding observed variancecovariance matrix. For a subset of vertices $A \subset N$, let $\Sigma_{A}$ denote the variancecovariance matrix of the variables in $X_{A}$, and define with $S_{A}$ the corresponding observed variance-covariance submatrix.

When the graph $G$ is decomposable, the likelihood of the data, under the graphical Gaussian model specified by $P$, nicely decomposes as follows (see e.g. [21]):

$$
p(x \mid \Sigma, G)=\frac{\prod_{c \in \mathcal{C}} p\left(x_{C} \mid \Sigma_{C}\right)}{\prod_{s \in \mathcal{S}} p\left(x_{S} \mid \Sigma_{S}\right)}
$$

where $C$ and $S$ respectively denote the set of cliques and the set of separators for the graph $G$, and:

$$
P\left(x_{C} \mid \Sigma_{C}\right)=(2 \pi)^{-\frac{n *|C|}{2}}\left|\Sigma_{C}\right|^{-n / 2} \exp \left[-1 / 2 \operatorname{tr}\left(S_{C}\left(\Sigma_{C}\right)^{-1}\right)\right]
$$

the same representation holds for $P\left(x_{S} \mid \Sigma_{S}\right)$.

A convenient prior for the parameters of the above likelihood is the hyper inverse Wishart distribution. It can be obtained from a collection of clique specific marginal inverse Wisharts as follows:

$$
l(\Sigma)=\frac{\prod_{C \in \mathcal{C}} l\left(\Sigma_{C}\right)}{\prod_{S \in \mathcal{S}} l\left(\Sigma_{S}\right)}
$$

where $l\left(\Sigma_{C}\right)$ is the density of an inverse Wishart distribution, with hyperparameters $T_{C}$ and $\alpha$, and similarly for $l\left(\Sigma_{S}\right)$. For the definition of the hyperparameters here we follow [21] and let $T_{C}$ and $T_{S}$ be the submatrices of a larger matrix $T_{0}$ of dimension $N \times N$, and choose $\alpha>N$. To complete the prior specification, for $P(G)$, we assume a uniform prior over all possible graphical structures.

It can be shown that, under the previous assumptions, the posterior distribution of the variance-covariance matrix $\Sigma$ is a hyper Wishart distribution with $\alpha+N$ degrees of freedom and a scale matrix given by:

$$
T_{n}=T_{0}+S_{n}
$$

where $S_{n}$ is the sample variance-covariance matrix. This result can be used for quantitative learning on the unknown parameters, for a given graphical structure.

In addition, the proposed prior distribution can be used to integrate the likelihood with respect to the unknown random parameters, obtaining the so-called marginal likelihood of a graph, which will be the main metric for structural learning, that involves choosing the most likely graphical structures. Such marginal likelihood is equal to: 


$$
P(x \mid G)=\frac{\prod_{C \in \mathcal{C}} p\left(x_{C}\right)}{\prod_{S \in \mathcal{S}} p\left(x_{S}\right)}
$$

in which

$$
p\left(x_{C}\right)=(2 \pi)^{-\frac{n *|C|}{2}} \frac{k(|C|, \alpha+n)}{k(|C|, \alpha)} \frac{\operatorname{det}\left(T_{0}\right)^{\alpha / 2}}{\operatorname{det}\left(T_{n}\right)^{(\alpha+n) / 2}}
$$

where $k(\cdot)$ is the multivariate gamma function, given by:

$$
k_{p}(a)=\pi^{\frac{p(p-1)}{4}} \prod_{j=1}^{p} \Gamma\left(a+\frac{1-j}{2}\right)
$$

By Bayes rule, the posterior probability of a graph is given by:

$$
P(G \mid x) \propto P(x \mid G) P(G)
$$

and, therefore, since we assume a uniform prior over the graph structures, maximizing the posterior probability is equivalent to maximizing the marginal likelihood. For graphical model selection purposes we shall thus search in the space of all possible graphs for the structure such that

$$
G^{*}=\arg \max _{G} P(G \mid x) \propto \arg \max _{G} P(x \mid G)
$$

The Bayesian approach does not force conditioning inferences on the (best) model chosen. The assumption of $G$ being random, with a prior distribution on it, allows any inference on quantitative parameters to be model averaged with respect to all possible graphical structures, with weights that correspond to the posterior probabilities of each graph. This is due to Bayes' Theorem:

$$
P(\Sigma \mid X)=P(\Sigma \mid x, G) P(G \mid x)
$$

However, in many real problems, the number of possible graphical structures could be very large and we may need to restrict the number of models to be averaged. This can be done efficiently, for example, following a simulation-based procedure for model search, such as Markov Chain Monte Carlo (MCMC) sampling.

In our context, given an initial graph, the algorithm samples a new graph using a proposal distribution. To guarantee irreducibility of the Markov chain, we follow [21] to test whether the proposed graph is decomposable. The newly sampled graph is then compared with the old graph, calculating the ratio between the two marginal likelihoods, if the ratio is greater than a predetermined threshold (acceptance probability), the proposal is accepted, otherwise it is rejected. The algorithm continues until practical convergence is reached.

\section{Empirical Application}

\subsection{Data Description}

We have selected all the publicly traded banks in the MENA region from Bureau Van Dijk's Bankscope database. The banks that have data availability limitations where dis- 
carded which resulted in a total sample size of 81 listed banks that belong to 14 different countries. The country list along with the corresponding percentage of banking assets for each bank type from MENA region total assets is described per year in Table 1.

Table 1. MENA countries banking assets distribution between bank types per year.

\begin{tabular}{|c|c|c|c|c|c|c|c|}
\hline Country & Bank Type & 2008 & 2009 & 2010 & 2011 & 2012 & 2013 \\
\hline \multirow[t]{4}{*}{$\mathrm{AE}$} & $\mathrm{CB}$ & 0.11 & 0.1 & 0.13 & 0.16 & 0.15 & 0.15 \\
\hline & CB.win & 1.3 & 1.22 & 0.96 & 0.87 & 0.67 & 0.69 \\
\hline & CB.sub & 7.54 & 7.86 & 7.91 & 7.68 & 7.77 & 7.47 \\
\hline & IB & 1.6 & 1.63 & 1.66 & 1.57 & 1.59 & 1.66 \\
\hline \multirow[t]{3}{*}{ SA } & CB.win & 5.74 & 6.03 & 5.71 & 5.32 & 5.4 & 5.21 \\
\hline & CB.sub & 0.96 & 1.01 & 1 & 0.98 & 1.06 & 1.02 \\
\hline & IB & 1.67 & 1.85 & 2 & 2.26 & 2.56 & 2.6 \\
\hline IL & $\mathrm{CB}$ & 8.65 & 8.76 & 9.03 & 8.81 & 8.36 & 8.15 \\
\hline \multirow[t]{4}{*}{ KW } & $\mathrm{CB}$ & 0.84 & 0.77 & 0.9 & 0.86 & 0.88 & 0.89 \\
\hline & CB.win & 1.41 & 1.46 & 1.32 & 1.27 & 1.28 & 1.25 \\
\hline & CB.sub & 1.49 & 1.4 & 1.38 & 1.35 & 1.42 & 1.49 \\
\hline & IB & 1.81 & 1.83 & 1.82 & 1.99 & 1.94 & 1.79 \\
\hline \multirow[t]{3}{*}{ QA } & CB.win & 0.89 & 0.75 & 0.81 & 0.81 & 0.88 & 0.99 \\
\hline & CB.sub & 1.66 & 1.77 & 1.96 & 2.37 & 2.8 & 3.06 \\
\hline & IB & 0.86 & 0.75 & 0.8 & 0.94 & 1.09 & 1.07 \\
\hline IR & IB & 1.44 & 1.89 & 1.97 & 2.17 & 2.34 & 2.85 \\
\hline \multirow[t]{3}{*}{$\mathrm{BH}$} & CB.win & 0.5 & 0.36 & 0.34 & 0.37 & 0.38 & 0.36 \\
\hline & CB.sub & 1.72 & 1.7 & 1.56 & 1.51 & 1.42 & 1.32 \\
\hline & IB & 0.69 & 0.72 & 0.74 & 0.72 & 0.65 & 0.63 \\
\hline \multirow[t]{3}{*}{ MA } & $\mathrm{CB}$ & 1.03 & 1.09 & 1.06 & 1.08 & 1.02 & 0.82 \\
\hline & CB.win & 0.41 & 0.39 & 0.43 & 0.48 & 0.26 & 0.4 \\
\hline & CB.sub & 1.08 & 1.14 & 1.1 & 1.12 & 0.72 & 0.92 \\
\hline \multirow[t]{2}{*}{ LB } & $\mathrm{CB}$ & 0.17 & 0.17 & 0.2 & 0.25 & 0.27 & 0.27 \\
\hline & CB.sub & 2.03 & 2.1 & 2.05 & 1.93 & 1.83 & 1.79 \\
\hline \multirow[t]{2}{*}{ JO } & $\mathrm{CB}$ & 0.19 & 0.17 & 0.24 & 0.26 & 0.25 & 0.23 \\
\hline & CB.sub & 1.08 & 0.93 & 0.87 & 0.88 & 0.85 & 0.79 \\
\hline \multirow[t]{2}{*}{$\mathrm{OM}$} & $\mathrm{CB}$ & 0.21 & 0.09 & 0.08 & 0.08 & 0.14 & 0.15 \\
\hline & CB.win & 1.04 & 0.72 & 0.76 & 0.75 & 0.82 & 0.82 \\
\hline \multirow[t]{2}{*}{ EG } & CB.win & 0.4 & 0.36 & 0.37 & 0.38 & 0.39 & 0.36 \\
\hline & IB & 0.24 & 0.14 & 0.14 & 0.15 & 0.15 & 0.15 \\
\hline \multirow[t]{2}{*}{ MT } & $\mathrm{CB}$ & 0.42 & 0.31 & 0.19 & 0.23 & 0.23 & 0.23 \\
\hline & CB.win & 0.34 & 0.24 & 0.22 & 0.14 & 0.17 & 0.18 \\
\hline TN & CB & 0.48 & 0.31 & 0.28 & 0.28 & 0.27 & 0.25 \\
\hline
\end{tabular}


Table 1 indicates that the highest proportions of bank assets in our sample can be attributed to Arab Emirates, Saudi Arabia, Israel, Kuwait and Qatar.

The banks in the sample are also classified according to four banking types: CBs group, which includes conventional banks that do not provide any type of Islamic financial services; CB-Win group, which includes conventional banks that provide Islamic financial services within their operations but do not operate a fully Islamic banking subsidiary; CB-Sub group, which includes conventional banks that provide Islamic financial services and operate an Islamic banking subsidiary; and IBs group, which includes fully fledged Islamic banks in all its services and subsidiaries. The 81 banks in the sample are distributed between the different banking groups to $19 \mathrm{CBs}, 24 \mathrm{CB}$-win, 17 CB-sub, $21 \mathrm{IBs}$, a more detailed distribution by country is shown in Table 2.

Table 2 indicates that IL represents a full CBs system, while IR represents a full IBs one. In terms of total assets, at the overall MENA level, the CB group represent $23.42 \%$ of them, the CB-win group $21.41 \%$, the CB-sub group $35.67 \%$ and the IBs group $19.49 \%$.

We use a dataset that represents market data on equities that extends over 89 months from January 2007 to May 2014. The data set is split into two main parts, the first is

Table 2. Distribution of bank type per country.

\begin{tabular}{ccccccc}
\hline Country & Country code & Gulf countries & CBs & CB-Win & CB-Sub & IBs \\
\hline $\begin{array}{c}\text { Kuwait } \\
\text { United Arab }\end{array}$ & KW & Yes & 2 & 3 & 1 & 4 \\
Emirates & AE & Yes & 1 & 4 & 6 & 4 \\
Oman & OM & Yes & 1 & 3 & - & - \\
Qatar & QA & Yes & - & 3 & 2 & 3 \\
Saudi Arabia & SA & Yes & - & 6 & 1 & 4 \\
Bahrain & BH & Yes & - & 2 & 2 & 2 \\
Iran & IR & Yes & - & - & - & 3 \\
$\begin{array}{l}\text { Total Number } \\
\text { of Banks }=57\end{array}$ & & & 4 & 21 & 12 & 20 \\
Israel & IL & No & 6 & - & - & - \\
Morocco & MA & No & 3 & 1 & 1 & - \\
Lebanon & LB & No & 1 & - & 2 & - \\
Jordan & JO & No & 1 & - & 2 & - \\
Malta & MT & No & 2 & 1 & - & - \\
Tunisia & TN & No & 2 & - & - & - \\
Egypt & EG & No & - & 1 & - & 1 \\
$\begin{array}{l}\text { Total Number } \\
\text { of Banks }=24\end{array}$ & & & 15 & 3 & 5 & 1 \\
$\begin{array}{l}\text { Total Number } \\
\text { of Banks }=81\end{array}$ & & & 19 & 24 & 17 & 21 \\
\hline & & & & & \\
\hline
\end{tabular}


during the crisis period, which extends from January 2007 to December 2009, and the second is after the crisis period, from January 2010 to May 2014. Table 3 provides the descriptive statistics of the the stock market return data for MENA countries.

\subsection{Contagion Network between Countries}

Before studying systemic risks, we describe the systematic effects of countries on bank performances.

Figure 1 shows the time evolution of the aggregated bank returns on a per country basis for the period from 2007 to 2014.

Figure 1 indicates the presence of high volatility for some countries' returns, which seems to be centered around the trend of Israel. Overall, countries with a high portion of Islamic banks, such as Saudi Arabia and Iran, are more volatile than countries with a

Table 3. MENA countries return descriptive statistics.

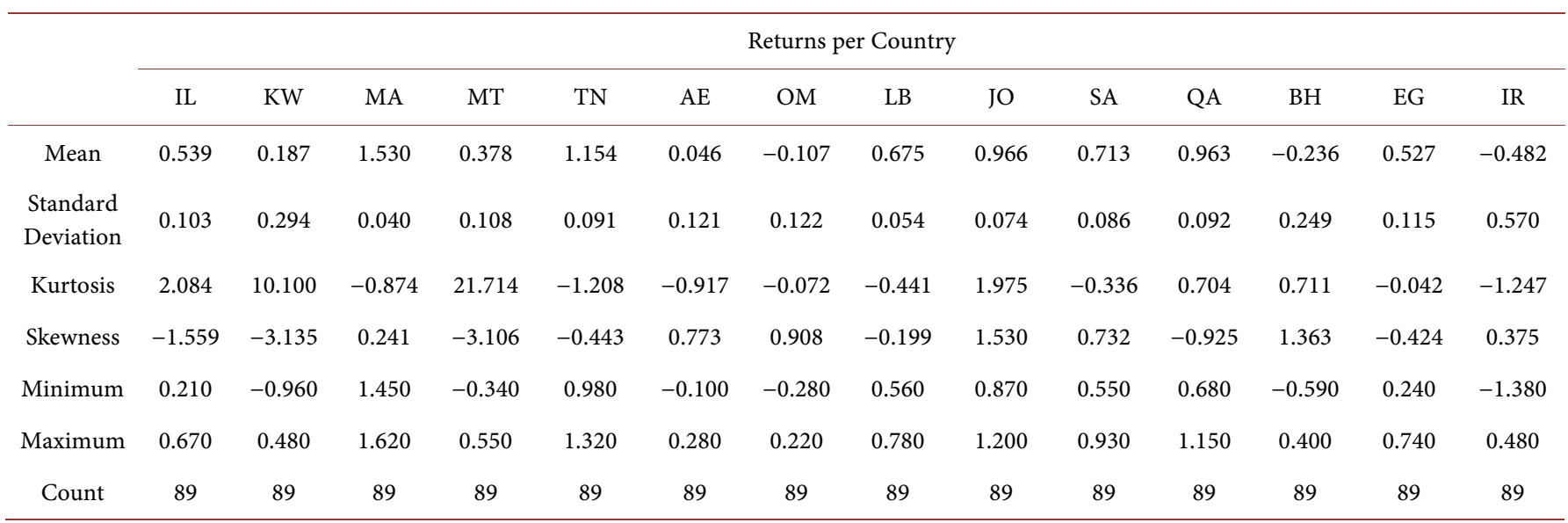

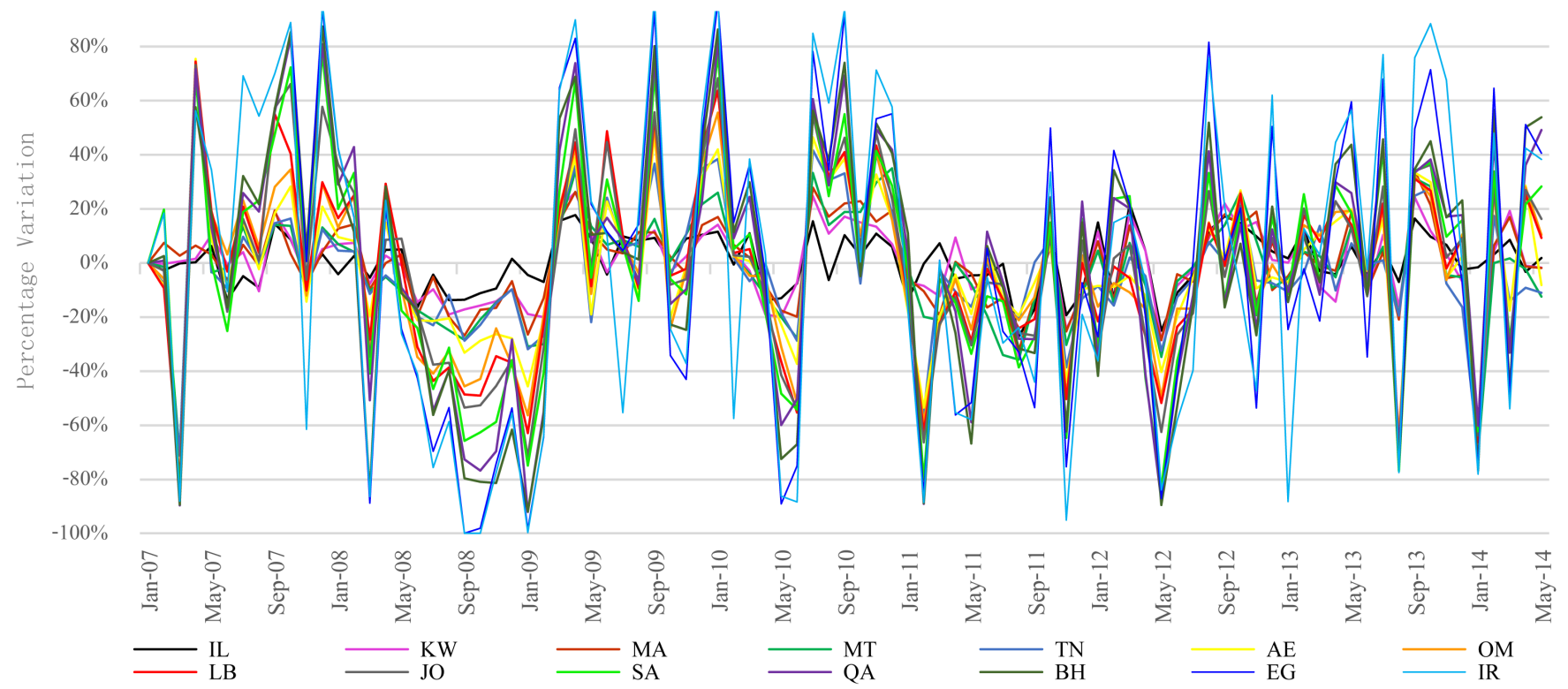

Figure 1. MENA countries stock-market return variation over the period 2007-2014. 
high portion of conventional banks, such as Tunisia. Having seen the systematic effects of countries, we examine if this volatility is transmitted by assessing the impact in terms of systemic risk, the main focus of our paper.

To achieve this aim we present the graphical Gaussian model obtained on the basis of the partial correlations between aggregate country returns, separately for the crisis period (2007-2009) and the post-crisis period (2010-2014). We have chosen the best model by means of a backward selection procedure that, starting from the fully connected model, progressively tests for edge removal using a significance level of $\alpha=0.05$. Figure 2 describes the selected graphical models during the crisis period and post crisis period.

In the above figure for the crisis and post crisis periods, the nodes with the highest number of edges are the most interrelated, we can determine the capacity of the corresponding countries as agents for systematic risk using centrality measures, and rank countries from the most to the least contagious.

Table 4 shows the centrality measures, introduced in Section 2, that are calculated on the basis of the graphical models in Figure 2.

The centrality measures in Table 4 show that the fully conventional banking system, represented by IL, has the highest rank for almost all the centrality measures of the selected models, whereas the fully Islamic banking system, represented by IR, ranks lowest during the crisis, but has a moderate increase in its contagion rank in the postcrisis period. This finding may suggest that the two systems are different in terms of systemic risk, with full Islamic banks being less contagious.

As for the dual banking systems, weak economies such as JO and LB are in relatively high ranks during and after the crisis, with the other weak economies moving upward in the ranks for the post crisis period. On the other hand, strong economies are relatively stable, as they have a moderate change in their ranks, except for $\mathrm{KW}$, which seems to follow the behavior of the full conventional system in both its rank and its returns variability through time. These findings suggest that the impact of the dual hybrid systems strongly depends on the country in which they are based.

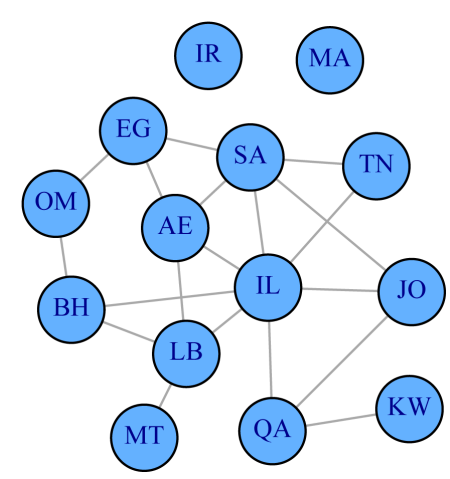

(a)

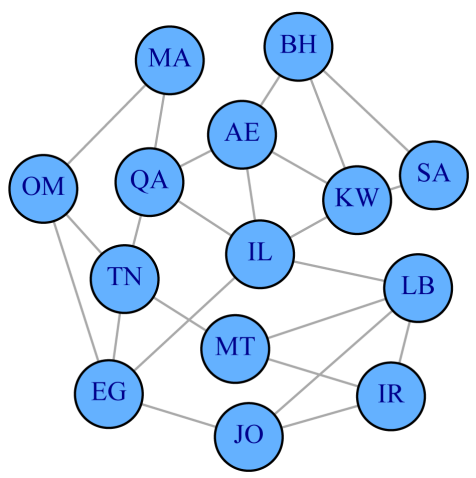

(b)

Figure 2. Contagion network between countries. (a) During-crisis network, (b) post-crisis network. 
Table 4. Centrality measures.

\begin{tabular}{ccccccc}
\hline & \multicolumn{2}{c}{ Node Degree } & \multicolumn{2}{c}{ Node Partial Correlation Degree } & \multicolumn{2}{c}{ Eigenvector Centrality } \\
\hline Country & During-Crisis & Post-Crisis & During-Crisis & Post-Crisis & During-Crisis & Post-Crisis \\
\hline IL & 7 & 5 & 3.69 & 2.22 & 0.52 & 0.43 \\
KW & 1 & 4 & 0.43 & 2.23 & 0.06 & 0.31 \\
MA & 0 & 2 & 0 & 0.78 & 0 & 0.14 \\
MT & 1 & 3 & 0.43 & 1.19 & 0.08 & 0.2 \\
TN & 2 & 4 & 0.86 & 1.52 & 0.24 & 0.28 \\
AE & 4 & 4 & 1.95 & 1.94 & 0.37 & 0.35 \\
OM & 2 & 3 & 1.17 & 1.27 & 0.12 & 0.2 \\
LB & 4 & 4 & 2.13 & 1.64 & 0.3 & 0.28 \\
JO & 3 & 3 & 1.75 & 1.31 & 0.29 & 0.21 \\
SA & 5 & 2 & 2.43 & 0.92 & 0.42 & 0.14 \\
QA & 3 & 4 & 1.38 & 1.43 & 0.22 & 0.33 \\
BH & 3 & 3 & 1.62 & 1.7 & 0.24 & 0.22 \\
EG & 3 & 4 & 1.55 & 1.64 & 0.23 & 0.3 \\
IR & 0 & 3 & 0 & 1.42 & 0 & 0.19 \\
\hline
\end{tabular}

We now consider the full time evolution of the eigenvector centrality measure by means of the Bayesian approach, which provides a stable averaged model inference on yearly basis as shown in Table 5 .

The Bayesian model eigenvector centrality measure in Table 5 shows that the fully conventional banking system combined with a strong economy, as in the case of IL, has a high systemic risk rank during and after the crisis (except for the year 2011). Whereas the fully Islamic banking system, represented by IR, starts from a low contagion rank during the crisis, and moves upward in the rank in the post-crisis period. This finding confirms the previous model results regarding the difference between the two systems in terms of systemic risk, with the full Islamic banks being less contagious during crisis period.

In terms of the dual banking systems, weak economies such as MA, MT, TN, JO and $\mathrm{LB}$ are in relatively high ranks during the crisis and remain there after the crisis (except for JO). On the other hand, strong economies with a high concentration of Islamic banks, as in the case of SA, start in low ranks during the crisis, move to higher ranks upon its materialization in 2009, and progress towards lowering their ranks after. Similarly, the Bayesian model shows that KW starts from a high contagion rank and progresses towards a lower one after the crisis.

The dispersion in the eigenvector centrality measure estimated from the Bayesian model around its yearly average, from 2007 to 2013, is provided in Figure 3.

Figure 3 reflects the high dispersion of the eigenvector centrality measure during the 2007-2008 crisis period around its yearly average, which is mainly led by countries of 
Table 5. Eigenvector centrality of the bayesian model.

\begin{tabular}{|c|c|c|c|c|c|c|c|}
\hline \multicolumn{8}{|c|}{ Eigenvector Centrality per Year } \\
\hline $\mathrm{IL}$ & 0.35 & 0.399 & 0.269 & 0.313 & 0.021 & 0.279 & 0.331 \\
\hline KW & 0.001 & 0.399 & 0.269 & 0.313 & 0.021 & 0.193 & 0.144 \\
\hline MA & 0.35 & 0.399 & 0.269 & 0.313 & 0.356 & 0.279 & 0.331 \\
\hline $\mathrm{TN}$ & 0.35 & 0.022 & 0.269 & 0.036 & 0.356 & 0.223 & 0.135 \\
\hline $\mathrm{AE}$ & 0.06 & 0.001 & 0.269 & 0.313 & 0.356 & 0.279 & 0.331 \\
\hline $\mathrm{OM}$ & 0.001 & 0.023 & 0.269 & 0.313 & 0.098 & 0.245 & 0.115 \\
\hline LB & 0.35 & 0.399 & 0.271 & 0.008 & 0.098 & 0.353 & 0.372 \\
\hline QA & 0.06 & 0.114 & 0.027 & 0.324 & 0.098 & 0.368 & 0.307 \\
\hline $\mathrm{BH}$ & 0.365 & 0.399 & 0.006 & 0.324 & 0.133 & 0.076 & 0.139 \\
\hline EG & 0.35 & 0.005 & 0.058 & 0.072 & 0.364 & 0.279 & 0.331 \\
\hline IR & 0.062 & 0.11 & 0.586 & 0.036 & 0.414 & 0.322 & 0.343 \\
\hline Yearly Average & 0.215 & 0.195 & 0.221 & 0.236 & 0.222 & 0.258 & 0.246 \\
\hline
\end{tabular}

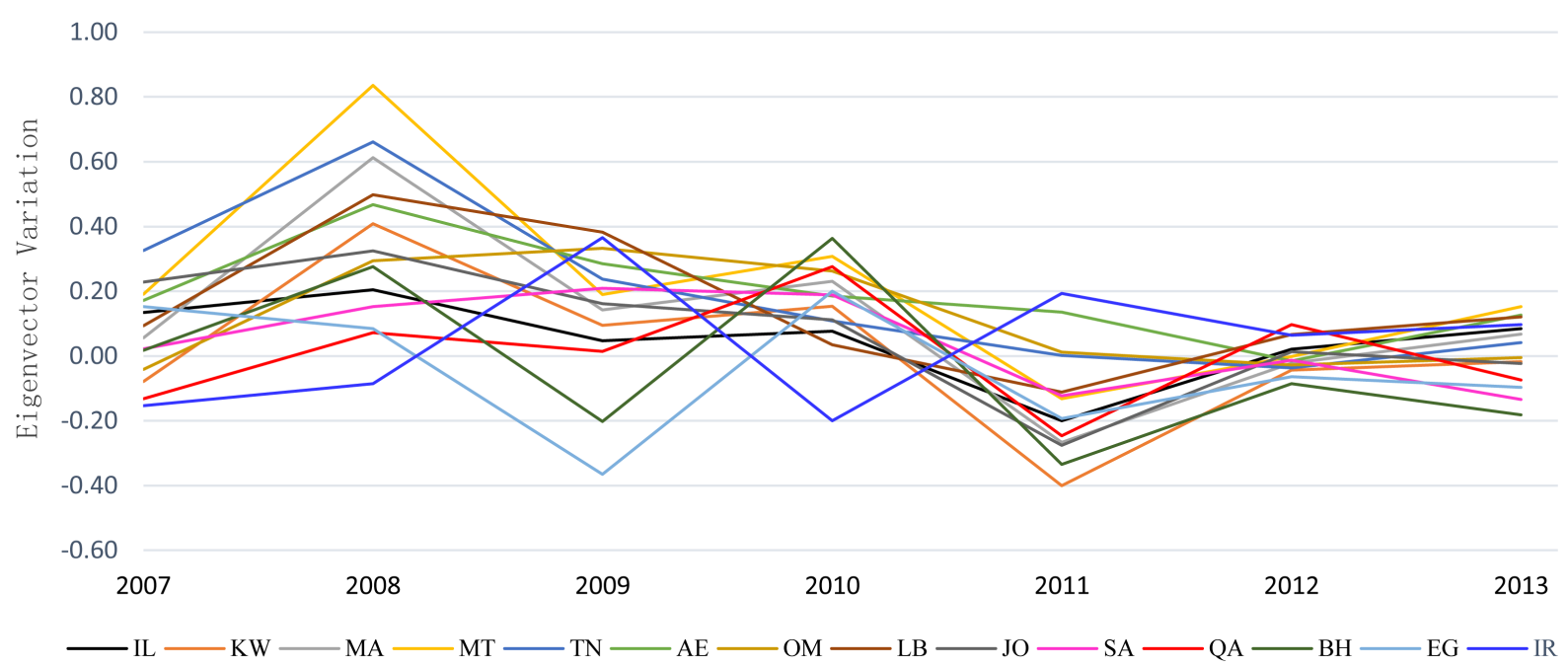

Figure 3. Countries eigenvector centrality variation around its yearly average.

higher conventional banking concentration, and reflects a lower extent of high dispersion during 2009 that is led by countries of higher Islamic banking concentration. For both systems, the dispersion around the mean is reduced in the following years. Overall, Figure 3 suggests that the countries have high differences in their contagion levels during the crisis, but have smaller differences after the crisis.

To summarize, our findings suggest that there is a difference between the con- 
ventional and the Islamic banking systems impact on systemic risk, not only in magnitude but also in timing as there is a one year time lag for the crisis effect on Islamic banks. In addition, a hybrid system within a strong economy may in general support a lower systemic risk which may be consistent with a diversification effect on the country's systemic level portfolio. Finally, we remark that the eigenvector centrality dispersion measure in Figure 3 may be beneficial as an early warning indicator of a crisis.

\section{Conclusions}

The main aim of this paper is to investigate whether and how Islamic financial services support financial stability, based on how they affect the country level systematic risk. To achieve this aim, we have proposed a correlation network approach based on graphical Gaussian models, both classical and Bayesian, with a set of related centrality measures, which may describe the systemic risk of each country.

Our results support the ability of the Islamic banking model to enhance financial and economic stability, but also the presence of a strong cross-country variability. These results confirm the findings provided by the literature. Our findings also clearly describe the different impact of the recent financial crisis on the systemic risk levels of each country.

Suggestions for future research involve further studying systemic risk in dual systems combining graphical models with standard bivariate measures such as MES, SRISK and $\triangle \mathrm{CoVaR}$. Furthermore, it would be important to let systemic risk to depend on variables such as the leverage and the size of the banking sectors and the market share of different banking types.

\section{Acknowledgements}

The authors acknowledge the financial support from the PRIN project MISURA: multivariate models for risk assessment, and of the $\mathrm{PhD}$ programme in Economics and management of technology at the University of Pavia. The paper has been written by Shatha Hashem, with the supervision of Professor Paolo Giudici.

\section{References}

[1] Islamic Financial Services Board (2014) Islamic Financial Services Industry Stability Report 2014. Technical Report, Islamic Financial Services Board, Bank Negara Malaysia, Kuala Lumpur.

[2] Shafique, A., Faheem, M.A. and Abdullah, I. (2012) Impact of Global Financial Crises on the Islamic Banking System: Analysis of Islamic Financial System during Financial Crunch 2008. Oman Chapter of Arabian Journal of Business and Management Review AJBMR, 1, 124-134. http://dx.doi.org/10.12816/0002166

[3] Aziz, Z.A. (2008) Enhancing the Resilience and Stability of the Islamic Financial System. BIS Review. 145, Bank for International Settlement: Islamic Financial Services Board and Institute of International Finance Conference, Kuala Lumpur, 1-5. http://www.bis.org/review/r081126c.pdf 
[4] Betz, F., Oprică, S., Peltonen, T.A. and Sarlin, P. (2014) Predicting Distress in European Banks. Journal of Banking \& Finance, 45, 225-241. http://dx.doi.org/10.1016/j.jbankfin.2013.11.041

[5] Baele L., Farooq M. and Ongena S. (2014) Of Religion and Redemption: Evidence from Default on Islamic Loans. Journal of Banking \& Finance, 44, 141-159. http://dx.doi.org/10.1016/j.jbankfin.2014.03.005

[6] Čihák, M. and Hesse, H. (2010) Islamic Banks and Financial Stability: An Empirical Analysis. Journal of Financial Services Research, 38, 95-113. http://dx.doi.org/10.1007/s10693-010-0089-0

[7] Abedifar, P., Molyneux, P. and Tarazi, A. (2013) Risk in Islamic Banking. Review of Finance, 17, 2035-2096. http://dx.doi.org/10.1093/rof/rfs041

[8] Beck, T., Demirgç-Kunt, A. and Merrouche, O. (2013) Islamic vs. Conventional Banking: Business Model, Efficiency and Stability. Journal of Banking \& Finance, 37, 433-447. http://dx.doi.org/10.1016/j.jbankfin.2012.09.016

[9] Hasan, M. and Dridi, J. (2011) The Effects of the Global Crisis on Islamic and Conventional Banks: A Comparative Study. Journal of International Commerce, Economics and Policy, 2, 163-200. http://dx.doi.org/10.1142/S1793993311000270

[10] Karim, B.A., Lee, W.S., Karim, Z.A. and Jais, M. (2012) The Impact of Subprime Mortgage Crisis on Islamic Banking and Islamic Stock Market. Procedia-Social and Behavioral Sciences, 65, 668-673. http://dx.doi.org/10.1016/j.sbspro.2012.11.182

[11] Imam, P. and Kpodar, K. (2013) Islamic Banking: How Has It Expanded? Emerging Markets Finance and Trade, 49, 112-137. http://dx.doi.org/10.2753/REE1540-496X490607

[12] Bourkhis, K. and Nabi, M.S. (2013) Islamic and Conventional Banks' Soundness during the 2007-2008 Financial Crisis. Review of Financial Economics, 22, 68-77. http://dx.doi.org/10.1016/j.rfe.2013.01.001

[13] Billio, M., Getmansky, M., Lo, A.W. and Pelizzon, L. (2012) Econometric Measures of Connectedness and Systemic Risk in the Finance and Insurance Sectors. Journal of Financial Economics, 104, 535-559. http://dx.doi.org/10.1016/j.jfineco.2011.12.010

[14] Chong, B.S. and Liu, M.H. (2009) Islamic Banking: Interest-Free or Interest-Based? PacificBasin Finance Journal, 17, 125-144. http://dx.doi.org/10.1016/j.pacfin.2007.12.003

[15] Khan, F. (2010) How "Islamic" Is Islamic Banking? Journal of Economic Behavior \& Organization, 76, 805-820. http://dx.doi.org/10.1016/j.jebo.2010.09.015

[16] Sundararajan, V. and Errico, L. (2002) Islamic Financial Institutions and Products in the Global Financial System: Key Issues in Risk Management and Challenges Ahead. IMF Working Paper, 2, 1-27. https://www.imf.org/external/pubs/cat/longres.aspx?sk=16109.0 http://dx.doi.org/10.5089/9781451859775.001

[17] Iqbal, M. and Llewellyn, D.T. (2002) Islamic Banking and Finance: New Perspectives on Profit Sharing and Risk. Edward Elgar Publishing, Inc., Cheltenham.

http://www.elgaronline.com/view/1840647876.xml http://dx.doi.org/10.4337/9781843765318

[18] Solé, J. (2008) Introducing Islamic Banks into Conventional Banking Systems. Journal of Islamic Economics, Banking and Finance, 4, 9-34. http://ibtra.com/pdf/journal/v4 n2 article1.pdf

[19] Ariffin, N., Archer, S. and Karim, R. (2009) Risks in Islamic Banks: Evidence from Empirical Research. Journal of Banking Regulation, 10, 153-163. http://dx.doi.org/10.1057/jbr.2008.27

[20] Lauritzen, S.L. (1996) Graphical Models. Oxford Statistical Science Series. Clarendon Press, 
Oxford.

https://global.oup.com/academic/product/graphical-models-9780198522195?cc=it\&lang=e $\underline{n \text { \&\# }}$

[21] Giudici, P. and Spelta, A. (2016) Graphical Network Models for International Financial Flows. Journal of Business \& Economic Statistics, 34, 128-138.

http://dx.doi.org/10.1080/07350015.2015.1017643

[22] Cerchiello, P. and Giudici, P. (2016) Conditional Graphical Models for Systemic Risk Estimation. Expert Systems with Applications, 43, 165-174.

http://dx.doi.org/10.1016/j.eswa.2015.08.047

[23] Benoit, S., Colliard, J.-E., Hurlin, C. and Perignon, C. (2015) Where the Risks Lie: A Survey on Systemic Risk. Working Paper.

https://halshs.archives-ouvertes.fr/halshs-01142014/document

[24] Segoviano, M.A. and Goodhart, C. (2009) Banking Stability Measures. IMF Working Paper No. 09, 1-54. https://www.imf.org/external/pubs/ft/wp/2009/wp0904.pdf

[25] Acharya, V.V., Pedersen, L.H., Philippon, T. and Richardson, M.P. (2010) Measuring Systemic Risk.

[26] Adrian, T. and Brunnermeier, M. (2011) CoVaR. Working Paper 17454, National Bureau of Economic Research.

[27] Huang, X., Zhou, H. and Zhu, H. (2011) Systemic Risk Contributions. Journal of Financial Services Research, 42, 55-83. http://dx.doi.org/10.1007/s10693-011-0117-8

[28] Brownlees, C.T. and Engle, R.F. (2015) Srisk: A Conditional Capital Shortfall Measure of Systemic Risk.

[29] Billio, M., Getmansky, M. and Pelizzon, L. (2012) Dynamic Risk Exposures in Hedge Funds. Computational Statistics \& Data Analysis, 56, 3517-3532. http://dx.doi.org/10.1016/j.csda.2010.08.015

[30] Diebold, F.X. and Ylmaz, K. (2014) On the Network Topology of Variance Decompositions: Measuring the Connectedness of Financial Firms. Journal of Econometrics, 182, 119-134. http://dx.doi.org/10.1016/j.jeconom.2014.04.012

[31] Hautsch, N., Schaumburg, J. and Schienle, M. (2014) Forecasting Systemic Impact in Financial Networks. International Journal of Forecasting, 30, 781-794. http://dx.doi.org/10.1016/j.ijforecast.2013.09.004

[32] Peltonen, T.A., Piloiu, A. and Sarlin, P. (2015) Network Linkages to Predict Bank Distress.

[33] Barigozzi, M. and Brownlees, C.T. (2014) NETS: Network Estimation for Time Series.

[34] Whittaker, J. (1990) Graphical Models in Applied Multivariate Statistics. Wiley Series in Probability and Mathematical Statistics, John Wiley and Sons, Chichester. http://eu.wiley.com/WileyCDA/WileyTitle/productCd-0471917508.html

[35] Corander, J. and Villani, M. (2006) A Bayesian Approach to Modelling Graphical Vector Autoregressions. Journal of Time Series Analysis, 27, 141-156. http://dx.doi.org/10.1111/j.1467-9892.2005.00460.x

[36] Carvalho, C.M. and West, M. (2007) Dynamic Matrix-Variate Graphical Models. Bayesian Analysis, 2, 69-97. http://dx.doi.org/10.1214/07-BA204

[37] Furfine, C. (2003) Interbank Exposures: Quantifying the Risk of Contagion. Journal of Money, Credit, and Banking, 35, 111-128. http://dx.doi.org/10.1353/mcb.2003.0004 
Submit or recommend next manuscript to SCIRP and we will provide best service for you:

Accepting pre-submission inquiries through Email, Facebook, LinkedIn, Twitter, etc. A wide selection of journals (inclusive of 9 subjects, more than 200 journals)

Providing 24-hour high-quality service

User-friendly online submission system

Fair and swift peer-review system

Efficient typesetting and proofreading procedure

Display of the result of downloads and visits, as well as the number of cited articles

Maximum dissemination of your research work

Submit your manuscript at: http://papersubmission.scirp.org/

Or contact am@scirp.org 